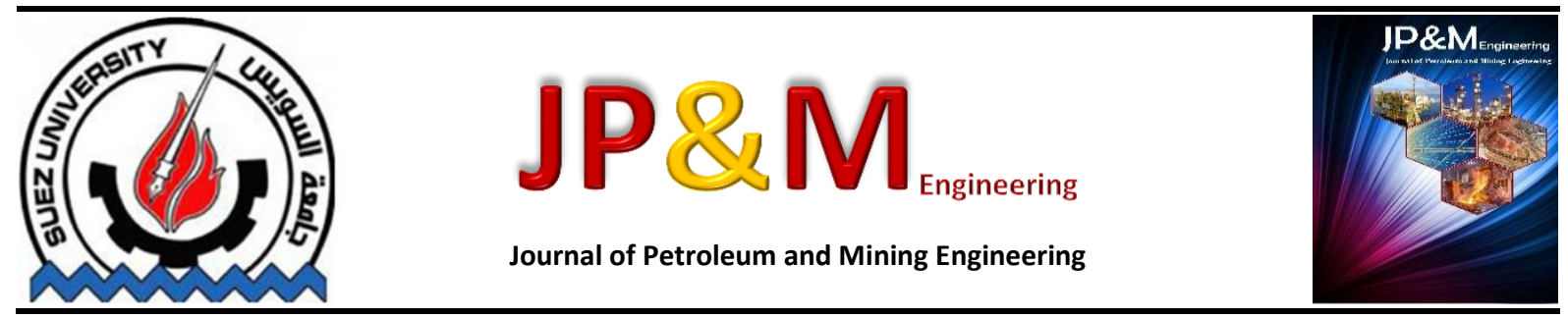

\title{
Annular Pressure Losses Prediction Using Power-Law Model with Polymer Water-Base Mud
}

\author{
George Kheir $^{a *}$, Ahmed El-Gibaly ${ }^{b}$, and Mohammed S. Farahat ${ }^{b}$ \\ a Halliburton \\ ${ }^{b}$ Faculty of Petroleum and Mining Engineering, Suez University (SU), Egypt \\ *Corresponding author Georgeazmy33@yahoo.com
}

\section{Keywords}

Bottomhole Pressure ;Calculation; Rheological models; Power-Law model; Polymer Water-Base Mud

\begin{abstract}
Bottomhole Pressure (BHP) determination is quite crucial in the success of the drilling operations, especially on tight-drilling window environment. The calculation becomes much more critical when drilling with near-balance bottomhole pressure on the unconventional drilling techniques like Managed Pressure Drilling (MPD). Although Pressure-While-Drilling (PWD) technology can provide measured values of Bottomhole Pressure, it is so expensive and needs circulation to convey readings. Also, in case of tool failure, it consumes a lot of time to trip out of hole in order to change the tool, especially on deep-well drilling. On this paper, Bingham, Power-Law, Herschel-Bulkley and API RP13D rheological models have been utilized to calculate the Annular Pressure Loss (APL) on a deep well with polymer Water-Base Mud (WBM). A comparative study between model-calculated and PWD-measured values of APL for 15 points along the wellbore was conducted on the calculation of Annular Pressure Loss. Power-Law model was found the most optimum rheological model for polymer Water-Base Mud, due to exhibiting no Yield Stress. Power-law model gave 35 psi average error which can be tolerated most of the time during drilling operations.
\end{abstract}

\section{Introduction}

\section{Managed Pressure Drilling (MPD) Technology}

On tight-drilling window environments or when Managed Pressure Drilling (MPD) is applied, the importance of real-time prediction of Bottomhole Pressure (BHP) cannot be overemphasized. The increase or decrease of BHP might easily result in NonProductive Time (NPT) by inducing formation breakdown or getting influx. In order to mitigate such incidents, BHP should be controlled and monitored at all time of the operations. Bottomhole Pressure is the summation of the hydrostatic pressure of the mud $\left(P_{\text {hyd. }}\right)$, the Annular Friction Pressure of the flow (APF) and the Surface Back-Pressure (SBP) in case of MPD as shown in the following equation:

$$
\mathrm{BHP}=\mathrm{P}_{\text {hyd. }}+\mathrm{AFP}+\mathrm{SBP}
$$

Hydrostatic Pressure of the mud is simply calculated with the Mud Weight (MW) and True Vertical Depth (TVD), however along the deep wellbore, MW will be considerably variant but this point is out of the paper scope. The Annular Pressure Loss (APL) is considered the most difficult term as the drilling fluids are non-Newtonian fluids at which the viscosity of the fluid depends on the temperature and the shear rate. To describe the thixotropic, pseudoplastic behavior of the drilling fluid, different rheological models are utilized where different assumptions are postulated.

Pressure-While-Drilling (PWD) is a recent technology that gives us continuous reading of BHP that allows to optimize the drilling operations and calibrate the rheological models. However, it is an expensive technology, doesn't work on connection and could cost a trip in case of tool failure which is quite frequent.

\section{Tazhong Field Overview}

The Tazhong field is located in the Tarim Basin, in the central part of Taklimakan Desert, Xinjiang Uyghur autonomous region of Northwest China. Since 1989, The Tarim field has grown to be a crucial hydrocarbon, especially gas field for China ${ }^{[1]}$ with 27 oil/gas discovered fields ${ }^{[2]}$ and total area of 560 thousands $\mathrm{km} 2$. The basin consists of a Paleozoic marine cratonic basin and a Meso-Cenozoic continental foreland basin. In the Tazhong Uplift, there are three sets of oil and gas stratum systems, of which the Ordovician traps are the largest in size and close to the oil-source beds with the most favorable conditions to form 
largescale oil and gas fields [3]. The structure is composed of 4 producing blocks with large networks of fractures which make drilling within this environment difficult. The well within this study was drilled in the eastern side of this structure which is a reef flat-lithology trap where the productive zone is the Ordovician fractured limestone. Table 1 shows the characteristics of the reservoir, while Figure 1 shows the location map for Tarim basin at Taklimakan desert in the north of China.

Table 1 Reservoir Characteristics [3]

\begin{tabular}{|l|l|}
\hline Reservoir Pressure (SG) & $1.11-1.20$ \\
\hline Reservoir Temperature $\left({ }^{\circ} \mathrm{C}\right)$ & $130-140$ \\
\hline Gas Density (SG) & $0.61-0.64$ \\
\hline CO2 Percentage & $1.6-3.2 \%$ \\
\hline $\mathrm{H} 2 \mathrm{~S}(\mathrm{ppm})$ & $11-33,000$ \\
\hline
\end{tabular}

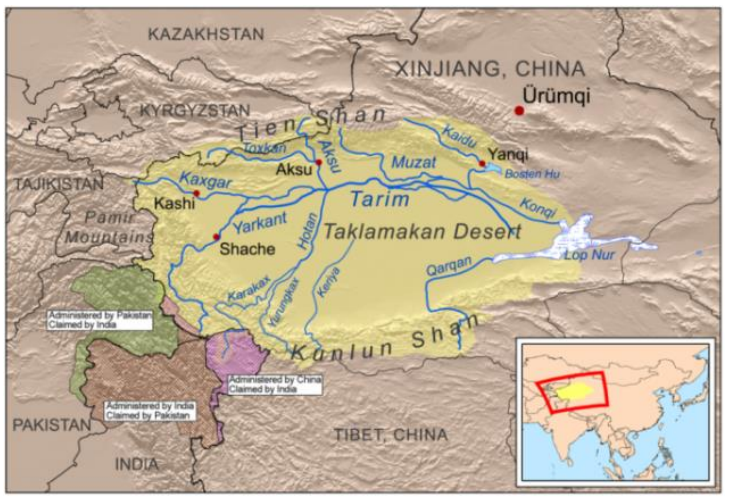

Figure 1 Tarim Basin, Taklamakan Desert Location Map.

The objectives for utilizing MPD technology on the well of the study were to drill and complete a 6" lateral from 6539 m MD/ 6516 m TVD to 7149 m MD horizontally within the Ordovician Limestone reservoir with minimal losses and no serious well control situations. The objectives of this well were almost met because TD was called earlier than expected with only $79 \mathrm{~m}$ at $7070 \mathrm{~m} \mathrm{MD}$ where they encountered huge mud losses that couldn't be handled via MPD.

\section{Materials and Methodology}

On an ultra-deep, recent horizontal well in China, Pressure-While-Drilling (PWD) technology was applied to get the actual measurement of BHP. The operator utilized Polymer Water-Base Mud (WBM) to reach the Cambrian reservoir. In addition, Bingham, Power-law, Herschel-Bulkley and API RP13D rheological models are utilized to predict the Annular Pressure Loss (APL) at 15 different points along the wellbore in addition to the Newtonian assumption for reference purpose.

The results from the different models were crossplotted versus the actual values that are measured by PWD. Analysis for the cross-plot was performed and the different statistical values were calculated for each model.

This study has been done on a well drilled in China few years ago. The section on focus is 6" sidetrack which was kicked off at $5585 \mathrm{~m}$ and reached Total Depth (TD) at $6647 \mathrm{~m}$ in the Cambrian dolomite reservoir sections. Polymer Water-Base Mud (WBM) was utilized to drill this section. Different mud weights have been used during the drilling of this section based on the well events. Tables 2, 3 and 4 are the input data utilized in calculating Annular Pressure Loss (APL) using the various rheological models. Table 2 shows the well configuration including the different casing strings with their setting depth.

Table 2 Well Configuration.

\begin{tabular}{|c|c|c|c|}
\hline (m) & $\begin{array}{l}\text { Bit } \\
\text { size } \\
(\mathrm{mm})\end{array}$ & $\begin{array}{r}\text { Casing } \\
\text { size }(\mathrm{mm})\end{array}$ & $\begin{array}{r}\text { Casing } \\
\text { depth }(m)\end{array}$ \\
\hline $0-500$ & 5444. & 339.7 & 500 \\
\hline $500-3900$ & $2^{311 .}$ & $\begin{array}{l}244.5 \\
(273)\end{array}$ & 3900 \\
\hline $3900-5570$ & $9^{215 .}$ & 177.8 & 5572 \\
\hline $5570-6000$ & $4_{4} 152$. & 127 & 6000 \\
\hline $6000-6647$ & $\begin{array}{l}152 . \\
4\end{array}$ & $\begin{array}{l}114.30 \\
\text { (Liner) }\end{array}$ & 6647 \\
\hline
\end{tabular}

Table 3 shows the mud properties of different mud weights used along the target section of the well. Mud rheological properties help calculating the friction pressure along the annulus. The thicker the mud, the higher the pressure loss, however viscosity is required to enhance the cutting lifting capacity of the mud and the well hole cleaning.

Table 3 Mud Properties of the Well.

\begin{tabular}{|l|c|r|r|c|}
\hline \multicolumn{1}{|c|}{ Name } & \multicolumn{2}{|c|}{ Value } & & \\
\hline $\begin{array}{l}\text { Mud } \\
\text { Weight } \\
\text { (g/cc) }\end{array}$ & 1.18 & 1.22 & 1.27 & 1.33 \\
\hline $\begin{array}{l}\text { Funnel } \\
\text { Viscosity (s) }\end{array}$ & 50 & 49 & $46-54$ & $46-56$ \\
\hline $\begin{array}{l}\text { Plastic } \\
\text { Viscosity } \\
\text { (MPa.s) }\end{array}$ & 20 & 20 & 20 & $20-21$ \\
\hline $\begin{array}{l}\text { Yield Point } \\
\text { (Pa) }\end{array}$ & 6 & 6 & $6-8$ & $8-9$ \\
\hline \multirow{3}{*}{$\begin{array}{l}\text { Fann } \\
\text { Readings }\end{array}$} & 15 & 15 & $17-19$ & $18-20$ \\
\cline { 2 - 5 } & 24 & 24 & $26-29$ & $29-31$ \\
\cline { 2 - 5 } & 3 & 3 & 4 & $5-6$ \\
\cline { 2 - 5 } & 2 & 2 & 3 & $4-5$ \\
\hline
\end{tabular}

Table 4 shows the Bottomhole Assembly (BHA) of the drill string during drilling the highlighted section. Well Sketch along with the BHA defines the annular 
clearance of the drilling fluid path. The cross-sectional area is critical for the annular velocity and the annular pressure losses.

Table 4 Bottomhole Assembly (BHA) of the Well

\begin{tabular}{|c|c|c|c|c|c|}
\hline \multicolumn{2}{|c|}{ Section $(\mathrm{m})$} & $5983-6378$ & \multicolumn{3}{|c|}{ Mud Weight $\mathrm{g} / \mathrm{cm} 3=1.27-1.40$} \\
\hline BHA & Name $\times$ specs & $\mathrm{OD}($ Inch / mm) & ID (Inch/mm) & Length (m) & Total Length (m) \\
\hline & $594 \times$ DP x S135 I & $3.5 / 88.9$ & $2.6 / 66.09$ & 5812.36 & 6378 \\
\hline & $39 \times \mathrm{HWDP} \times \mathrm{S} 135 \mathrm{I}$ & $3.5 / 88.9$ & $2.13 / 54$ & 363.15 & 565.64 \\
\hline & $18 \times \mathrm{DP} \times \mathrm{S} 135 \mathrm{I}$ & $3.5 / 88.9$ & $2.6 / 66.09$ & 173.22 & 202.49 \\
\hline & NMDC $\times S 135$ & $4.75 / 120.7$ & $2.2 / 56$ & 9.30 & 29.27 \\
\hline & MWD & $4.75 / 120.7$ & $2.2 / 56$ & 5.12 & 19.97 \\
\hline & $\mathrm{HCIM}$ & $4.75 / 120.7$ & $2.2 / 56$ & 3.80 & 14.85 \\
\hline & PWD & $4.75 / 120.7$ & $2.63 / 67$ & 2.8 & 11.05 \\
\hline & Float sub & $4.8 / 122$ & $2.25 / 57.2$ & 2.78 & 8.25 \\
\hline 量 & $1.25^{\circ}$ Motor & $4.75 / 1200$ & $2.2 / 56$ & 5.22 & 5.47 \\
\hline & PDC Bit & $6 / 152.4$ & & 0.25 & 0.25 \\
\hline
\end{tabular}

The following tables (Table $5 \& 6 \& 7$ ) show the relevant inputs and Pressure-While-Drilling (PWD) readings of 15 different points along the wellbore. The bottomhole pressure is recorded by PWD, and then the annular pressure losses are derived from the recorded data. Annular Pressure Losses are also calculated using data like BHA, well sketch and mud properties via four different rheological models. Then the calculated and the measured data are compared so as to explore the best rheological model that could describe the behavior of the mud rheology during drilling this well.

Table 5 shows the measured depth, mud weight, flow rate and PWD-measured bottomhole pressure for each of the 15 points along the wellbore

Table 6 shows how to process the PWD-measured bottomhole pressure so as to calculate the measured Annular Pressure Losses. The hydrostatic pressure for each point is calculated based on the True Vertical Depth (TVD). The Wellhead Pressure (WHP) applied by Table 5 Measured data (Depth, Mud weight, Flow rate \& BHP) the Managed Pressure Drilling choke is also taken into consideration when calculating the Annular Pressure Losses. Then the summation of WHP and hydrostatic head is subtracted from the total bottomhole pressure to get the annular friction loss.

Table 7 shows some remarks that have been taken during drilling the section. The remarks are mainly the Total Gas percentage during drilling these different points. The gas is a different phase that enters the continuous drilling fluid phase. This gas might lead to different annular pressure losses due to the different flow regime and friction pressure calculations for the gaseous fluids. The gas would also be a special consideration in case of Oil-Base Mud (OBM) because of its ability to dissolve and hide up within the solution and sudden break out on surface. Usually higher gases along the annulus would give less friction pressure in the annulus. 


\begin{tabular}{|c|c|c|c|c|c|c|c|c|c|}
\hline & \multirow{2}{*}{$\#$} & \multicolumn{2}{|c|}{ Depth } & \multicolumn{2}{|c|}{ Mud Weight } & \multicolumn{2}{|c|}{ Flow Rate } & \multicolumn{2}{|c|}{ BHP } \\
\hline & & $\mathrm{m}$ & $\mathrm{ft}$ & sg & ppg & liter/sec & gpm & Mpa & psi \\
\hline $\mathrm{d}$ & 1 & 5740 & 18832 & 1.18 & 9.8 & 9 & 143 & 68.9 & 9993 \\
\hline \# & 2 & 5770 & 18930 & 1.18 & 9.8 & 9 & 143 & 69 & 10008 \\
\hline$\varangle$ & 3 & 5800 & 19029 & 1.18 & 9.8 & 9 & 143 & 69.1 & 10022 \\
\hline$I$ & 4 & 5840 & 19160 & 1.18 & 9.8 & 8.8 & 139 & 69.2 & 10037 \\
\hline$m$ & 5 & 5868 & 19252 & 1.18 & 9.8 & 9 & 143 & 69.4 & 10066 \\
\hline N & 6 & 5880 & 19291 & 1.22 & 10.2 & 8.2 & 130 & 73.6 & 10675 \\
\hline$\#$ & 7 & 5950 & 19521 & 1.27 & 10.6 & 8 & 127 & 76.4 & 11081 \\
\hline 7 & 8 & 6020 & 19751 & 1.27 & 10.6 & 8 & 127 & 76.3 & 11066 \\
\hline$I$ & 9 & 6090 & 19980 & 1.27 & 10.6 & 8 & 127 & 76.4 & 11081 \\
\hline m & 10 & 6130 & 20112 & 1.27 & 10.6 & 8 & 127 & 77 & 11168 \\
\hline$m$ & 11 & 6200 & 20341 & 1.33 & 11.1 & 8 & 127 & 79.5 & 11531 \\
\hline 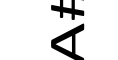 & 12 & 6240 & 20472 & 1.33 & 11.1 & 8 & 127 & 79.9 & 11581 \\
\hline$I$ & 13 & 6280 & 20604 & 1.34 & 11.2 & 8 & 127 & 80 & 11603 \\
\hline$m$ & 14 & 6340 & 20801 & 1.34 & 11.2 & 8 & 127 & 79.9 & 11589 \\
\hline BHA\#4 & 15 & 6370 & 20899 & 1.4 & 11.7 & 7.8 & 124 & 83.5 & 12111 \\
\hline
\end{tabular}

Table 6 Processing Measured data (Depth, WHP, ECD, TVD, Hydrostatic Pressure. and APL)

\begin{tabular}{|c|c|c|c|c|c|c|c|c|c|c|}
\hline & \multirow{2}{*}{ \# } & \multicolumn{2}{|c|}{ Depth } & \multicolumn{2}{|c|}{ WHP } & \multicolumn{2}{|c|}{ ECD } & \multirow{2}{*}{$\begin{array}{c}\text { TVD } \\
\mathrm{ft}\end{array}$} & \multirow{2}{*}{$\begin{array}{l}\text { Hyd. Pressure } \\
\text { psi }\end{array}$} & \multirow{2}{*}{$\begin{array}{c}\text { APL } \\
\text { psi }\end{array}$} \\
\hline & & m & $\mathrm{ft}$ & Mpa & psi & ppg & sg & & & \\
\hline \multirow{5}{*}{$\underset{\frac{1}{ \pm}}{\frac{7}{\pi}}$} & 1 & 5740 & 18832 & 0.7 & 102 & 10.20 & 1.23 & 18832 & 9626 & 266 \\
\hline & 2 & 5770 & 18930 & 0.8 & 116 & 10.21 & 1.23 & 18855 & 9638 & 254 \\
\hline & 3 & 5800 & 19029 & 0.9 & 131 & 10.21 & 1.23 & 18879 & 9650 & 242 \\
\hline & 4 & 5840 & 19160 & 1.7 & 247 & 10.21 & 1.23 & 18910 & 9665 & 125 \\
\hline & 5 & 5868 & 19252 & 1.8 & 261 & 10.22 & 1.23 & 18932 & 9677 & 128 \\
\hline \multirow{5}{*}{$\underset{\frac{\pi}{ \pm}}{\frac{N}{n}}$} & 6 & 5880 & 19291 & 2.2 & 319 & 10.84 & 1.30 & 18941 & 10010 & 346 \\
\hline & 7 & 5950 & 19521 & 2.5 & 363 & 11.22 & 1.35 & 18996 & 10450 & 268 \\
\hline & 8 & 6020 & 19751 & 2.2 & 319 & 11.19 & 1.34 & 19012 & 10459 & 288 \\
\hline & 9 & 6090 & 19980 & 2.1 & 305 & 11.20 & 1.34 & 19029 & 10468 & 308 \\
\hline & 10 & 6130 & 20112 & 3.4 & 493 & 11.28 & 1.35 & 19038 & 10473 & 202 \\
\hline \multirow{4}{*}{ 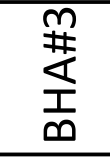 } & 11 & 6200 & 20341 & 1.2 & 174 & 11.64 & 1.40 & 19055 & 10977 & 379 \\
\hline & 12 & 6240 & 20472 & 1.7 & 247 & 11.68 & 1.40 & 19064 & 10983 & 352 \\
\hline & 13 & 6280 & 20604 & 1.3 & 189 & 11.70 & 1.40 & 19073 & 11071 & 344 \\
\hline & 14 & 6340 & 20801 & 1 & 145 & 11.68 & 1.40 & 19087 & 11079 & 365 \\
\hline BHA\#4 & 15 & 6370 & 20899 & 0.8 & 116 & 12.20 & 1.46 & 19094 & 11579 & 416 \\
\hline
\end{tabular}

Table 7 Operation Remarks at different points.

\begin{tabular}{|c|c|c|c|c|}
\hline & \multirow{2}{*}{ \# } & \multicolumn{2}{|c|}{ Depth } & \multirow{2}{*}{ Operation Remarks } \\
\hline & & $\mathbf{m}$ & ft & \\
\hline 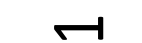 & 1 & 5740 & 18832 & \multirow{3}{*}{ TG $<5 \%$} \\
\hline \# & 2 & 5770 & 18930 & \\
\hline & 3 & 5800 & 19029 & \\
\hline \multirow{2}{*}{$\frac{T}{n}$} & 4 & 5840 & 19160 & \multirow{3}{*}{$\begin{array}{l}\mathrm{TG}=47 \% \\
\mathrm{TG}=52 \% \\
\mathrm{TG}=25 \%\end{array}$} \\
\hline & 5 & 5868 & 19252 & \\
\hline \multirow{5}{*}{$\underset{+}{+1}$} & 6 & 5880 & 19291 & \\
\hline & 7 & 5950 & 19521 & \multirow{4}{*}{ TG $<20 \%$ and Intermittent PWD data all the time } \\
\hline & 8 & 6020 & 19751 & \\
\hline & 9 & 6090 & 19980 & \\
\hline & 10 & 6130 & 20112 & \\
\hline \multirow{4}{*}{$\underset{\frac{1}{ \pm}}{m}$} & 11 & 6200 & 20341 & \multirow{3}{*}{ TG $<10 \%$ and intermittent PWD data } \\
\hline & 12 & 6240 & 20472 & \\
\hline & 13 & 6280 & 20604 & \\
\hline & 14 & 6340 & 20801 & \\
\hline ВНА\#4 & 15 & 6370 & 20899 & \\
\hline
\end{tabular}




\section{Results}

The following tables (Table 8 and 9) show the results of Annular Pressure Loss calculation via Newtonian-fluid assumptions besides four different rheological models (Bingham, Power-law, HerschelBulkley and API RP13D) for 15 points at different depths. The PWD-measured values are mentioned so as to calculate the error and the error percentage. The PWD-measured values were used as references for the results of the model-calculated values.

Bingham model postulates a linear stress-strain behavior of viscosity with a departure from the origin, usually called "Yield Point". Bingham model doesn't take into consideration "shear thinning" effect where the fluid viscosity decreases at higher strain rates. Power-Law model on the other hand stresses the shear thinning effect without any Yield limit. The shear thinning behavior is expressed with a power function of two parameters: "Flow Behavior Index" and "Consistency Constant".

Table 8 shows the Annular Pressure loss values as they were calculated by Bingham model and PowerLaw model. The error was calculated by subtracting the calculated value from the PWD-measured value. Then the error percentage was calculated by dividing the error by the PWD-measured value. Newtonian assumption is pressure friction calculation based on a single-value viscosity that keeps constant regardless of the strain rate. It is the same as Bingham model without Yield Point. Herschel-Bulkley model is believed to be the most accurate model as it combines the features of Bingham Yield Point with Power-Law shear thinning behavior. API RP13D model tried to make a better use of the six-theta readings via utilizing the low-strain readings in the low shear region and the high-strain readings in the high shear region.

Table 8 Bingham \& Power law APL compared to measured values
Table 9 shows the Annular Pressure loss values as they were calculated by the Newtonian-assumption, Herschel-Bulkley model and API RP13D model. The error was calculated by subtracting the calculated value from the PWD-measured value. Then the error percentage was calculated by dividing the error by the PWD-measured value.

Figure 2 is a cross-plot between the calculated and the measured values of the Annular Pressure Loss for the different models. On the cross-plot, the points are staked together because the depth differences weren't that much.

The cross-plot shows Bingham model huge offset from the PWD-measured values which is referred to the much higher than reality plastic viscosity values of Bingham which lead to higher calculated friction losses. The Newtonian assumption gives the lowest values on the plot which are much lower than the actual PWD-measured values. That is referred to the ignoring of the pseudo-plastic behavior of the drilling fluid. It is pretty much clear that the closest values to the PWD-measured values are Power-Law model and Herschel-Bulkley model values.

percentages are the only positive values as the calculated pressure loss is always less than the measured value due to ignoring the pseudo-plasticity. The 4th and 5th points had huge error percentage as big Total Gas percentages were out during drilling these points as per Table-7. The high gas cut led to lower actual pressure losses while the calculating models don't take into consideration the gas effect. Along the rest of the points, there is an average amount of error that differs from each model to the other. This residual error is maybe due to the combination of cutting effect, drill string rotating effect, thermal effect and/or pipe eccentricity effect.

\begin{tabular}{|c|c|c|c|c|c|c|c|}
\hline \multirow[t]{2}{*}{$\#$} & \multirow{2}{*}{$\begin{array}{l}\text { Measured } \\
\text { APL }\end{array}$} & \multicolumn{3}{|c|}{ Bingham } & \multicolumn{3}{|c|}{ Power Law } \\
\hline & & Error \% & Error & APL & Error \% & Error & APL \\
\hline 1 & 266 & -94 & -249 & 515 & -23 & -61 & 327 \\
\hline 2 & 254 & -104 & -264 & 518 & -30 & -75 & 329 \\
\hline 3 & 242 & -115 & -279 & 521 & -37 & -89 & 331 \\
\hline 4 & 125 & -319 & -398 & 522 & -163 & -202 & 327 \\
\hline 5 & 128 & -313 & -400 & 528 & -162 & -207 & 335 \\
\hline 6 & 346 & -50 & -172 & 518 & 9 & 31 & 315 \\
\hline 7 & 268 & -94 & -253 & 522 & -32 & -86 & 354 \\
\hline 8 & 288 & -83 & -240 & 528 & -24 & -70 & 358 \\
\hline 9 & 308 & -74 & -227 & 535 & -18 & -55 & 363 \\
\hline 10 & 202 & -167 & -337 & 539 & -82 & -164 & 366 \\
\hline 11 & 379 & -92 & -347 & 726 & 2 & 8 & 371 \\
\hline 12 & 352 & -108 & -379 & 731 & -6 & -22 & 374 \\
\hline 13 & 344 & -114 & -393 & 736 & -9 & -32 & 376 \\
\hline 14 & 365 & -104 & -379 & 744 & -4 & -15 & 380 \\
\hline 15 & 416 & -80 & -332 & 748 & 10 & 40 & 376 \\
\hline
\end{tabular}

Table 9 Newtonian, Herschel-Bulkley \& API RP13D APL compared to measured values 


\begin{tabular}{|c|c|c|c|c|c|c|c|c|c|c|}
\hline \multirow[t]{2}{*}{$\#$} & \multirow{2}{*}{$\begin{array}{l}\text { Measured } \\
\text { APL }\end{array}$} & \multicolumn{3}{|c|}{ Newtonian Fluid } & \multicolumn{3}{|c|}{ Herschel-Bulkley } & \multicolumn{3}{|c|}{ API RP13D } \\
\hline & & Error \% & Error & APL & Error \% & Error & APL & Error \% & Error & APL \\
\hline 1 & 266 & 62 & 166 & 100 & -17 & -45 & 311 & -34 & -90 & 356 \\
\hline 2 & 254 & 60 & 153 & 101 & -23 & -59 & 313 & -41 & -104 & 358 \\
\hline 3 & 242 & 58 & 140 & 102 & -30 & -73 & 315 & -49 & -119 & 361 \\
\hline 4 & 125 & 20 & 25 & 100 & -150 & -187 & 312 & -187 & -233 & 358 \\
\hline 5 & 128 & 19 & 25 & 103 & -149 & -191 & 319 & -185 & -237 & 365 \\
\hline 6 & 346 & 73 & 252 & 94 & 13 & 45 & 301 & 0 & -1 & 347 \\
\hline 7 & 268 & 65 & 175 & 93 & -35 & -95 & 363 & -54 & -144 & 412 \\
\hline 8 & 288 & 67 & 194 & 94 & -28 & -79 & 368 & -53 & -152 & 440 \\
\hline 9 & 308 & 69 & 212 & 96 & -21 & -64 & 373 & -45 & -138 & 446 \\
\hline 10 & 202 & 52 & 106 & 96 & -86 & -174 & 375 & -123 & -247 & 449 \\
\hline 11 & 379 & 74 & 281 & 98 & -14 & -52 & 431 & -35 & -131 & 510 \\
\hline 12 & 352 & 72 & 254 & 98 & -23 & -82 & 434 & -46 & -162 & 514 \\
\hline 13 & 344 & 71 & 245 & 99 & -27 & -94 & 438 & -51 & -174 & 518 \\
\hline 14 & 365 & 73 & 265 & 100 & -21 & -77 & 442 & -43 & -158 & 523 \\
\hline 15 & 416 & 76 & 318 & 98 & -6 & -23 & 439 & -25 & -105 & 521 \\
\hline
\end{tabular}

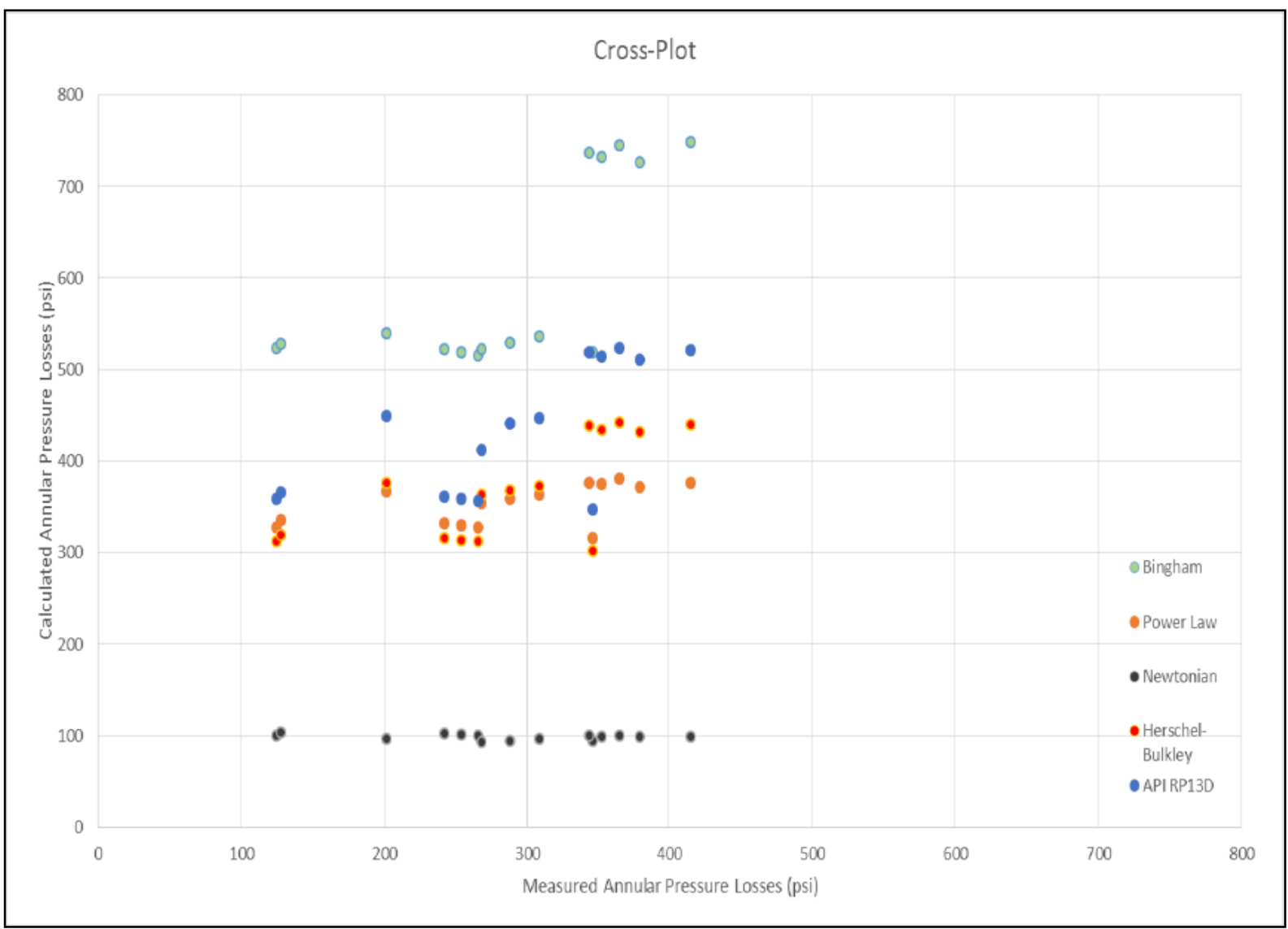

Figure 2 a cross-plot between the calculated and the measured values of the Annular Pressure Loss for the different models. 


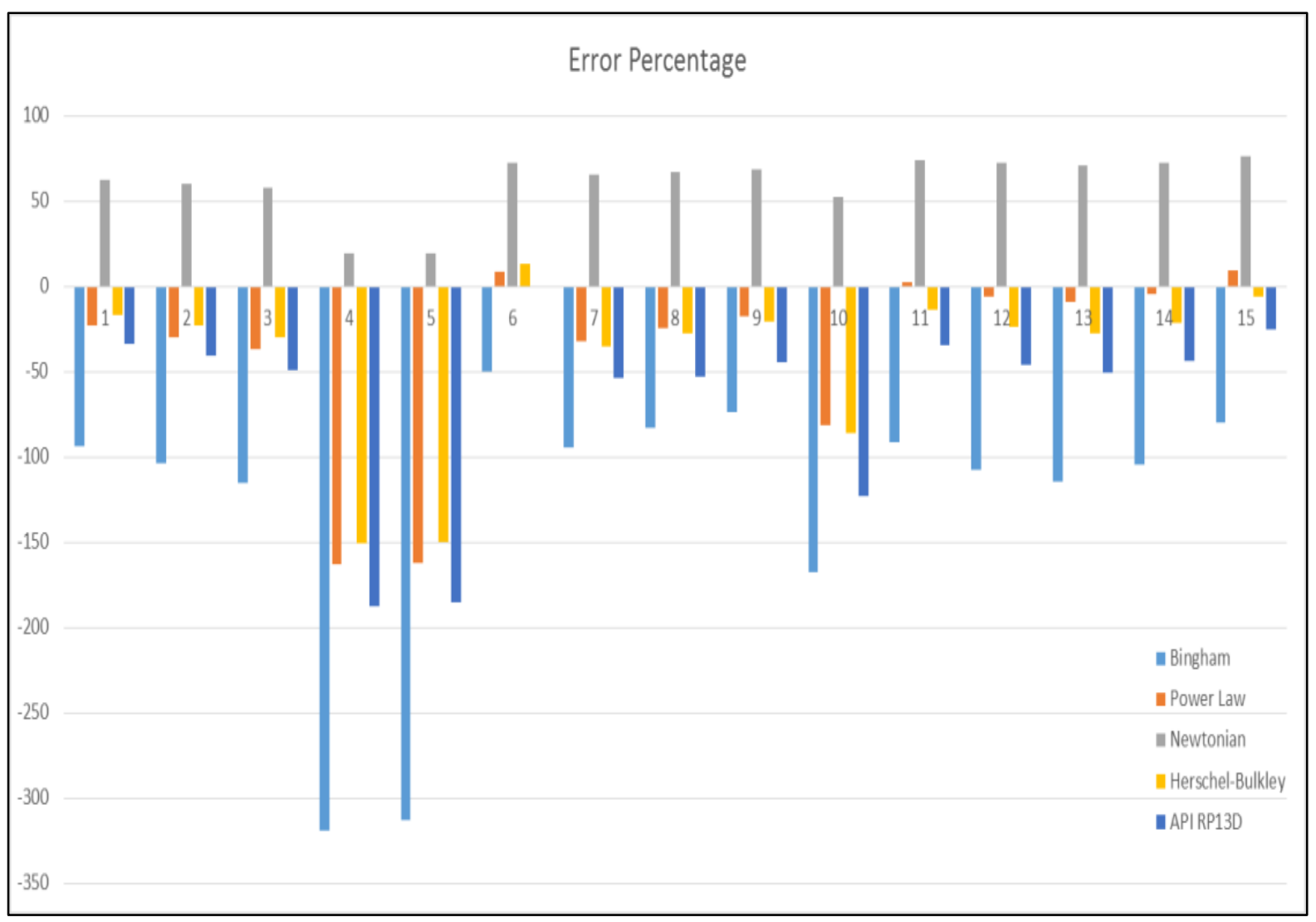

Figure 2 Error percentage graph for different rheological models.

Table 10 Statistics of the results (Points \#4, \#5 \& \#10 are excluded due to unreliable PWD readings)

\begin{tabular}{|c|ccccc|}
\hline Model & Newtonian & Bingham & $\begin{array}{c}\text { Power } \\
\text { Law }\end{array}$ & $\begin{array}{c}\text { Herschel- } \\
\text { Bulkley }\end{array}$ & API RP13D \\
\hline Average Error & 221.2 & -292.9 & -35.5 & -58.3 & -123.1 \\
\hline Average Error Percentage & 68.5 & -92.6 & -13.5 & -19.4 & -39.6 \\
\hline Mean Absolute Error (MAE) & 221.2 & 292.9 & 48.7 & 65.8 & 123.1 \\
\hline Mean Absolute Percentage Error & 68.5 & 92.6 & 17.0 & 21.5 & 39.6 \\
\hline Mean Square Error (MSE) & 51825 & 90461 & 3074 & 4765 & 17134 \\
\hline $\begin{array}{c}\text { Root Mean Square Deviation } \\
\text { (RMSD) / Standard Deviation (SD) }\end{array}$ & 227.7 & 300.8 & 55.4 & 69.0 & 130.9 \\
\hline $\begin{array}{c}\text { Normalized Root-Mean-Square } \\
\text { Deviation / Coefficient of Variation } \\
\text { of the RMSD, CV(RMSD) }\end{array}$ & 1.282 & 1.361 & 0.431 & 0.494 & 0.755 \\
\hline
\end{tabular}

Table 10 shows the statistical parameters for the different models results. It is pretty clear that PowerLaw model is the best fitting model with the measured values with an average error of -35 psi (35 psi higher than the measured value) and an average error percentage of $-13.5 \%$. Herschel-Bulkley model comes second in terms of matching with the PWD-measured data with an average error of $-58 \mathrm{psi}$ and an average error percentage of $-19.4 \%$.

\section{Discussion}

Several observations can be noticed from the output tables and graphs. Many of the observations can be explained in the light of each model assumptions while other needs a review for the drilling conditions. The following items are the observation along with its possible explanation:

- Newtonian assumption give the lowest estimation at all points (average error $=221$ psi \& average error percentage $=68.5 \%$ ). That is because most of drilling fluids are non-Newtonian fluids which show different effective viscosities with different strain rate. It is just calculated for referencing.

- Bingham models outputs are too much higher than the measured values which the highest error percentage (average error $=-293$ psi \& average error percentage $=-92.6 \%$ ). Bingham model by assumptions, doesn't take shear-thinning effect into consideration. This makes Bingham model values of APL are always higher than the actual 
values due to the higher apparent viscosity of Bingham model.

- Newtonian values and Bingham values are the lower and higher limits of prediction, respectively. Newtonian hypothesis gives the lowest values as it doesn't take "yielding limit" or "Shear-thinning" into consideration so it uses always much lower values for apparent viscosity, while Bingham model gives the higher values due to assuming much higher apparent viscosity and yield point ${ }^{[4]}$.

- API 13D model gives values less than Bingham but with high error percentages (average error $=-123 \mathrm{psi}$ $\&$ average error percentage $=-39.6 \%)$. API 13D model always gives values higher than Power law as it is using the lowest readings of viscometer so in this readings shear-thinning effect is much less than the higher values.

- Power law values and Herschel-Bulkley values are the best readings (Average error percentage of Power-law is $-13.5 \%$ while of Herschel-Bulkley is 19.4\%). In the first 5 points Power law values are higher, and then it starts to give lower values than Herschel-Bulkley values. In the first 5 points, Power law values were higher than Herschel-Bulkley values and less accurate because flow rate was high and then Power Law values became lower than Herschel-Bulkley at the rest of points.

- Large percentage of error in all models in points \#4 and \#5 because high gas percentages adversely affected PWD readings. PWD measurement wasn't reliable at point \#10.

- Surprisingly, Power-law model was the best matching model while Herschel-Bulkley model (the widely-accepted and most commonly-used model in drilling industry all over the world) came second in accuracy. This proves that Polymer Water-Base Mud exhibits no Yield Stress.

- The constant amount of error that appears in all points is due to the effects of combination of factors like:

a. It was found that the drillstring rotation raises the bottomhole pressure. It means that an extra friction pressure is added due to the drillstring rotation ${ }^{[5]}$. Rotation of drillstring is not considered in any model till the moment; however it has an effect on the bottomhole pressure. (almost 1 psi pressure loss per $1 \mathrm{rpm}$ )

b. Drilling was proceeding with less than 3 meter per hour ROP which doesn't provide any considerable amount of cuttings to increase APL.

c. The hole TVD was deep enough to make the downhole temperature too high. In Higher temperature, the viscosity drops which leads to the pressure losses reduction ${ }^{[6]}$.

d. The consistent amount of gases during drilling causes annular pressure losses to be lower than expected.

- The high error in points \#4 \& \#5 is due to the amount of gases came out of the well. Gas was around $50 \%$ during drilling of this interval. At point
\#10, PWD reading was unreasonable due to possible instantaneous malfunction or some other event during drilling.

\section{Conclusions}

Power-law model was found the best matching with Pressure-While-Drilling measured data with 35 psi average error (14\%) in Annular Pressure Loss calculation with Polymer Water-Base Mud. HerschelBulkley model came second in accuracy with average error 58 psi average error (20\%). Both of the models take into consideration the shear-thinning effect of the non-Newtonian fluids as a power function, however Power-Law model doesn't assume a Yield Stress meanwhile Herschel-Bulkley model assumes it. This leads to different indexes and consistency coefficients for each model of them. Polymer WaterBase Mud doesn't exhibit Yield Stress.

It is evident too that even with the best matching model; there is always a residual error that offsets the modelled value from the measured one. This residual error is attributed to many of the classical assumptions of the rheological models such as stationary, well-centered drillstring and isothermal assumptions. To drill, drillstring rotation is necessary which approximately adds 1 psi extra pressure loss per each rpm. The high temperature, encountered when drilling a deep reservoir (which is our case), changes the mud effective weight and rheology relevantly.

\section{References}

[1] Boliang, H., 1992, Petroleum Geology and Prospects of Tarim (Talimu) Basin, China, In Giant Oil and Gas Fields of the Decade, 1978-1988, AAPG Memoir 54, Halbouty, M.T., editor, Tulsa: American Association of Petroleum Geologists.

[2] Karen Teo, "Doubts over Sinopec oil find in Tarim", The Standard (January 4, 2005)". thestandard.com.hk. Archived from the original on March 10, 2011

[3] Mcmillan, W. S. (2010). “Overcoming Drilling Challenges in Northwest China using an Innovative MPD Technique." SPE/IADC Managed Pressure Drilling and Underbalanced Operations Conference and Exhibition.

[4] "A Rheological Model for Drilling Fluids and Cement Slurries", I.h. Gucuyener - Middle East Oil Technical Conference and Exhibition - 1983

[5] "Modeling the Effect of Pipe Rotation on Pressure Loss Through Tool Joint", Binh Bui - SPETT 2012 Energy Conference and Exhibition - 2012

[6] "High-Temperature, High-Pressure Rheology of WaterBased Muds", N.j. Alderman-A. Gavignet-D. Guillot-G.c. Maitland - Proceedings of SPE Annual Technical Conference and Exhibition - 1988 